\title{
Structure and Properties of Biodegradable PLLA/ZnO Composite Membrane Produced via Electrospinning
}

\author{
Daria A. Goncharova ${ }^{1, *}$, Evgeny N. Bolbasov ${ }^{2}\left(\mathbb{D}\right.$, Anna L. Nemoykina ${ }^{3}$, Ali A. Aljulaih ${ }^{4,5}$, \\ Tamara S. Tverdokhlebova ${ }^{2}$, Sergei A. Kulinich ${ }^{4,6,7, *(1)}$ and Valery A. Svetlichnyi ${ }^{1}$ (D) \\ 1 Laboratory of Advanced Materials and Technology, Tomsk State University, Tomsk 634050, Russia; \\ v_svetlichnyi@bk.ru \\ 2 Laboratory of Hybrid Plasma Systems, National Research Tomsk Polytechnic University, \\ Tomsk 634050, Russia; ebolbasov@gmail.com (E.N.B.); aramat_tts@mail.ru (T.S.T.) \\ 3 Laboratory of Biopolymers and Biotechnology, Tomsk State University, Tomsk 634050, Russia; \\ nemoykina@rambler.ru \\ 4 Department of Mechanical Engineering, Tokai University, Hiratsuka, Kanagawa 259-1259, Japan \\ 5 Division of Physical Science and Engineering, King Abdullah University of Science and Technology (KAUST), \\ Thuwal 23955-6900, Saudi Arabia; ali.julaih@kaust.edu.sa \\ 6 Research Institute of Science and Technology, Tokai University, Hiratsuka, Kanagawa 259-1259, Japan \\ 7 School of Natural Sciences, Far Eastern Federal University, Vladivostok 690091, Russia \\ * Correspondence: dg_va@list.ru (D.A.G.); skulinich@tokai-u.jp (S.A.K.)
}

Citation: Goncharova, D.A.; Bolbasov, E.N.; Nemoykina, A.L.; Aljulaih, A.A.; Tverdokhlebova, T.S.; Kulinich, S.A.; Svetlichnyi, V.A. Structure and Properties of Biodegradable PLLA/ZnO Composite Membrane Produced via Electrospinning. Materials 2021, 14, 2. https://dx.doi.org/10.3390/ma14010 002

Received: 20 November 2020 Accepted: 18 December 2020 Published: 22 December 2020

Publisher's Note: MDPI stays neutral with regard to jurisdictional claims in published maps and institutional affiliations.

Copyright: () 2020 by the authors. Licensee MDPI, Basel, Switzerland. This article is an open access article distributed under the terms and conditions of the Creative Commons Attribution (CC BY) license (https: / / creativecommons.org/ licenses/by/4.0/).

\begin{abstract}
These days, composite materials based on polymers and inorganic nanoparticles (NPs) are widely used in optoelectronics and biomedicine. In this work, composite membranes of polylactic acid and ZnO NPs containing 5-40 wt.\% of the latter NPs were produced by means of electrospinning. For the first time, polymer material loaded with up to $40 \mathrm{wt}$. $\%$ of $\mathrm{ZnO}$ NPs (produced via laser ablation in air and having non-modified surface) was used to prepare fiber-based composite membranes. The morphology, phase composition, mechanical, spectral and antibacterial properties of the membranes were tested by a set of analytical techniques including SEM, XRD, FTIR, UV-vis, and photoluminescence spectroscopy. Antibacterial activity of the materials was evaluated following standard procedures (ISO 20743:2013) and using S. aureus and E. coli bacteria. It is shown that incorporation of 5-10 wt.\% of NPs led to improved mechanical properties of the composite membranes, while further increase of $\mathrm{ZnO}$ content up to $20 \mathrm{wt}$ \% $\%$ and above resulted in their noticeable deterioration. At the same time, the antibacterial properties of $\mathrm{ZnO}$-rich membranes were more pronounced, which is explained by a larger number of surface-exposed $\mathrm{ZnO}$ NPs, in addition to those embedded into the bulk of fiber material.
\end{abstract}

Keywords: PLLA/ZnO composite membranes; ZnO nanoparticles; pulsed laser ablation; antibacterial properties

\section{Introduction}

Biodegradable polymers and their composites are widely used in diverse areas of human activities, from prototyping to packaging and biomedicine. One of the most commonly used biodegradable polymers is polylactide or poly-L-lactic acid (PLLA) whose biomedical applications cover transplanting materials, those for regenerative medicine, wound dressing, targeting delivery, and so on [1]. For more efficient use of such polymers, their modification is often necessary to provide them with required functional properties [2]. For instance, addition of $\mathrm{Ca}$ and $\mathrm{P}$ compounds or antibacterial agents and microelements render such biomedical materials with properties that promote bone tissue regeneration or faster wound healing. Diverse functional additives or modifiers can be either deposited on the surface or incorporated into the bulk of PLLA, in the latter case the effect of prolonged functional effect being realized [3]. 
Recently, because of the wide spread of antibiotic-resistant bacteria, for antibacterial use, in addition to traditional antibiotics, inorganic and hybrid nanoparticles (NPs) are extensively studied and tested as such NPs are known not to allow bacteria to develop resistance. In this respect, along with traditionally and long-used Ag NPs, those of ZnO are probably the most popular antibacterial nanomaterial [4-7].

Thus, $\mathrm{ZnO}$ NPs can be considered promising for use in biomedical materials and medications. Furthermore, it is worth mentioning that $\mathrm{Zn}$ is one of important microelements for normal functioning of human body [8,9], being an essential component for successful resistance against viruses including COVID-19 [10]. Recent studies demonstrated that $\mathrm{ZnO}$ NPs, together with photocatalytic therapy (irradiation with UVA-1), caused cytotoxicity of human head and neck squamous cell carcinoma in vitro [11]. In cosmetology, $\mathrm{ZnO}$ nanomaterials has proved to be effective in UV-protective creams $[12,13]$. Nanocomposites of polymers reinforced with ZnO NPs to improve their mechanical and antibacterial properties and capable of absorbing UV light can be used in food packaging [14,15]. Polymers incorporated with $\mathrm{ZnO}$ also demonstrate better mechanical properties and shape-memory effect, which makes them attractive for 3D printing [16]. When embedded into polymer, $\mathrm{ZnO} N$ Ps can provide additional protection against corrosion with a prolonged release of inhibitor and self-healing ability of its composite coating [17]. ZnO nanomaterial incorporated in polystyrene not only improves the quality of film, making it a denser, smoother and uniform layer for electron transfer in solar cells, but also increases contact area between hydrophilic $\mathrm{ZnO}$ and the hydrophobic active layer [18].

Polymer composites based on $\mathrm{ZnO}$ and fibers produced via electrospinning were found to exhibit improved antimicrobial effect when compared with conventional materials $[19,20]$ and demonstrated a wide range of applications as filters [21], bandage materials [22], and tissue frames [23]. Depending on potential applications, there are several methods of preparing composites of polymers with $\mathrm{ZnO}$ [22], such as fiber posttreatment after electrospinning [19], coaxial electrospinning to give rise to a core-shell fiber structure, encapsulation of active agent before mixing it with solution for electrospinning, or mixing active agent with its polymer solution immediately before electrospinning procedure. In Ref. [20], the authors compared mechanical properties and antibacterial activity of PLLA/ ZnO composites obtained by electrospinning of $\mathrm{ZnO}$ dispersion in PLLA solution and by a combination of electrospinning of polymer solutions with electrospraying of nano-ZnO dispersions.

Virovska and coauthors compared photocatalytic activity and antibacterial action of PLLA/ZnO produced via electrospinning with ZnO NPs, which were either embedded into the fibers or localized on their surface [24]. Antibacterial activity was shown to be more pronounced when $\mathrm{ZnO}$ nanomaterial was located on the material surface [20,24]. However, in some cases, prolonged release of $\mathrm{ZnO}$ is needed, for instance for controlling cell differentiation [25]. It should be added that so far, the maximum concentration of $\mathrm{ZnO}$ NPs loaded into PLLA via electrospinning was $23 \mathrm{wt} . \%$ [24]. Typically, for testing mechanical and antibacterial properties, PLLA/ZnO composites with low NP loads (below $5 \mathrm{wt} . \%)$ were reported $[20,25]$. Thus, investigation of PLLA/ZnO membranes with various $\mathrm{ZnO}$ loads is a timely task which will permit to understand better the structure, properties and behavior of such membranes, as well as possible areas of their application.

In the present work, we prepared and investigated composite membranes of PLLA incorporated with antibacterial ZnO NPs, which are potentially promising for wound bandaging and as adhesive pads in regenerative medicine. The main purpose of this research was to study the effect of the content of incorporated ZnO NPs on physicochemical properties and bactericidal effect of the produced membranes. The novelty and originality of this work are primarily underpinned with the following: (1) NPs of $\mathrm{ZnO}$ with «pure» (non-modified and not-passivated) surface were prepared via laser ablation in air, which provided us with a unique $\mathrm{ZnO}$ nanomaterial. (2) Composite membranes with $\mathrm{ZnO}$ loads as high as up to $40 \mathrm{wt} . \%$ were prepared via electrospinning of solution that contained dis- 
persed nanoparticles. This allowed us to study the mechanical and antibacterial properties of biomedical membranes with a wider range of embedded $\mathrm{ZnO}$ agent.

\section{Materials and Methods}

\subsection{Preparation of PLLA/ZnO Composite Membranes}

PLLA/ZnO composite membranes were electrospun from polymer solutions containing ZnO NPs prepared as nanopowder by means of the pulsed laser ablation in air technique. Nanosecond pulsed Nd:YAG laser was applied, with wavelength, pulse duration, pulse energy and frequency being $1064 \mathrm{~nm}, 7 \mathrm{~ns}, 150 \mathrm{~mJ}$, and $20 \mathrm{~Hz}$, respectively [19]. The use of this method, with $\mathrm{Zn}$ as target ablated in air and with no other precursors, permitted to generate $\mathrm{ZnO}$ NPs with pure and active surface, which is believed to be promising for biomedical applications [19]. The dispersions were prepared by mixing 0 , $0.3,0.6,1.2$ or $2.4 \mathrm{~g}$ of $\mathrm{ZnO}$ NPs in $93 \mathrm{~g}$ of chloroform in a glass reactor for $10 \mathrm{~h}$ at room temperature until a uniform white liquid was achieved. Then, 7, 6.7, 6.4, 5.8, or $4.6 \mathrm{~g}$ of poly-L-lactic acid (PL18, Corbion Purac, Netherlands) was added, after which the product was magnetically stirred for another $10 \mathrm{~h}$ at room temperature to achieve a uniform viscous white liquid.

$40 \mathrm{~mL}$ of as-prepared polymer dispersion was electrospun in a typical procedure using a NANON-NF-01 electrospinning setup (MECC Co., Ltd., Fukuoka, Japan), with working parameters being as follows: a flow of polymer solution of $1 \mathrm{~mL} / \mathrm{min}$, voltage of $27 \mathrm{kV}$, cylindrical collector speed of $50 \mathrm{rpm}$, and a needle-collector distance of $17 \mathrm{~cm}$. The formed material was heat-treated to get rid of residual organic solvent. For this, it was placed in a drying cabinet, where it was heated to a temperature of $100^{\circ} \mathrm{C}$ and kept at this temperature for $12 \mathrm{~h}$. The obtained material was cooled to room temperature and placed in sealed plastic bags. Thus, samples with $\mathrm{ZnO}$ load of $0,5,10,20$, and $40 \mathrm{wt} . \%$ were fabricated (hereafter denoted as PLLA, PLLA/ZnO_5\%, PLLA/ZnO_10\%, PLLA/ZnO_20\%, and PLLA/ZnO_40\%, respectively).

\subsection{Characterization of PLLA/ZnO Composite Membranes}

The surface morphology of PLLA and PLLA/ZnO composite membranes was studied by scanning electron microscopy (SEM, VEGA 3 SBH, Tescan, Brno, Czech Republic). Energy dispersive X-ray spectroscopy (EDX, AztecLive Lite Xplore 30, Oxford Instruments, UK) was used for elemental analysis. Obtained SEM images were analyzed by using the Image J software (National Institutes of Health, USA).

The crystal structure of PLLA and PLLA/ZnO composite membranes was analyzed by X-ray diffractometry (XRD), for which a XRD 6000 model (from Shimadzu, Kyoto, Japan) was used. Phase identification and quantitative analysis of XRD patterns were conducted using the database PDF4.

The water contact angle was measured via the sessile drop method using a contact angle goniometer (EasyDrop, Krüss, Germany). At least five measurements were carried out on different surface sites, after which their results were averaged. The surface density of the membranes was measured following the standard procedures previously described elsewhere [26]. Three samples sized as $10 \times 10 \mathrm{~cm}^{2}$ were taken, weighed, while their thickness was measured. The density was evaluated as the mass per volume [26].

Strength and elongation of PLLA and PLLA/ZnO composite membranes with sizes of $60 \times 20 \mathrm{~mm}^{2}$ and thickness of $166 \pm 20 \mu \mathrm{m}$ were studied using an Instron 3369 material testing machine (Instron, model 2519-102, USA) equipped with a $50 \mathrm{~N}$ load cell at a traverse speed of $10 \mathrm{~mm} / \mathrm{min}$. At least five samples were tested for each composition.

Fourier-transform infrared (FTIR) spectra were registered by a spectrometer (Nicolet 6700, Thermo Fisher Scientific, Waltham, MA, USA). UV-Vis absorption spectra of powder $\mathrm{ZnO}$, as well as of PLLA and PLLA/ZnO composite membranes, were examined by the diffuse-reflection spectroscopy (DRS) technique on a Cary 100 spectrophotometer (Varian, Australia) with accessory DRA-CA-30I (Labsphere, USA) in the range of 200-800 nm. The obtained absorption spectra were used to evaluate the bandgap values $\left(\mathrm{E}_{\mathrm{g}}\right)$ of the $\mathrm{ZnO}$ 
powder and PLLA/ZnO composite membranes in accordance with the Tauc method [27]. Photoluminescence (PL) spectra of the samples were recorded at room temperature by means of spectrofluorometer (CM 2203, Solar, Belarus) with an excitation wavelength of $310 \mathrm{~nm}$.

\subsection{Antibacterial Activity of PLLA/ZnO Composite Membranes}

Antibacterial activity of the prepared composite membranes was tested in accordance with the standard ISO 20743:2013 [28]. The method compares growth of bacteria on the control sample (sample PLLA in this study) and on the tested ones (PLLA/ZnO membranes with different $\mathrm{ZnO}$ content in our case). The tests were conducted with two bacterial strains: the gram-positive $S$. aureus (test strain ATCC 25923) and gram-negative E. coli (test strain B-6954, Russian Collection of Microorganisms). Both the methodology and conditions of the experiments were previously presented in greater detail elsewhere [19]. The value of antibacterial activity $(A)$ was determined as:

$$
A=\left(\lg C_{\mathrm{t}}-\lg C_{0}\right)-\left(\lg T_{\mathrm{t}}-\lg T_{0}\right)=F-G
$$

where $F$ and $G$ are the values observed on the control and ZnO-loaded PLLA membranes, respectively; $C_{0}, C_{t}, T_{0}$ and $T_{t}$ are the average number of bacteria $(C F U / \mathrm{mL}$ ) obtained on three control samples $(C)$ or on three $\mathrm{ZnO}$-loaded ones $(T)$ immediately after inoculation $\left(C_{0}\right.$ and $\left.T_{0}\right)$ and after $24 \mathrm{~h}$ of incubation $\left(C_{\mathrm{t}}\right.$ and $\left.T_{\mathrm{t}}\right)$. Note that in this model, for $T_{\mathrm{t}} \leq 1$, the value of $\lg T_{\mathrm{t}}$ is considered equal to 0 .

Depending on the experimentally determined value of $A$, the tested material is treated as either bacteriostatic $\left(C_{t}>T_{t}\right)$ or bactericidal $\left(T_{t}=0\right)$. Taking into account that the bactericidal effect implies the death of all bacteria during the incubation and that $C_{0} \approx T_{0}$, formula (1) for the maximum value of experimental $A$ can be modified and presented as Formula (2):

$$
A_{\max } \approx \lg C_{\mathrm{t}}
$$

\section{Results}

\subsection{Physico-Chemical Properties of PLLA/ZnO Composite Membranes}

Figure 1 presents SEM images of samples PLLA (a) and PLLA/ZnO with different $\mathrm{ZnO}$ loading (b-e), with corresponding histograms that present fiber size distribution shown as insets. It is seen that the initial PLLA membranes were formed as randomly crossed fibers, the latter fibers having diameters of $1.1 \pm 0.24 \mu \mathrm{m}$. Incorporation of $\mathrm{ZnO}$ NPs into PLLA is seen to result in a decrease of fiber diameters down to $40 \%$ of those in the unloaded sample in panel (a). In addition, the distribution of diameters in the ZnO-loaded membranes becomes bimodal, as they tend to have sizes about $0.2 \mu \mathrm{m}$, and from 0.5 to $0.7 \mu \mathrm{m}$ (see Figure 1 and Table 1 ). It is also well seen in panels (b-e) that the number of $\mathrm{ZnO}$ NPs is visually larger along their increase in the initial solution used for electrospinning.

At the same time, the number of visual defects (often observed as aggregates) in the fibers incorporated with $\mathrm{ZnO}$ NPs is seen in Figure 1 to grow as the membranes are doped with heavier loads of nanomaterial (see panels (b) to (e)). Because the viscosity of starting polymer with NPs is reduced when more NPs are added, the average diameter of the electrospun fibers they give rise to should become lower. This agrees well with what one can see in Figure 1. It should be noted that there is no linear relationship between the concentration of added ZnO NPs and the decrease in diameters of produced fibers, which is probably explained by the fact that the conductivity of the starting polymer solution changes along its viscosity as more nanomaterial is added as filler [29]. 

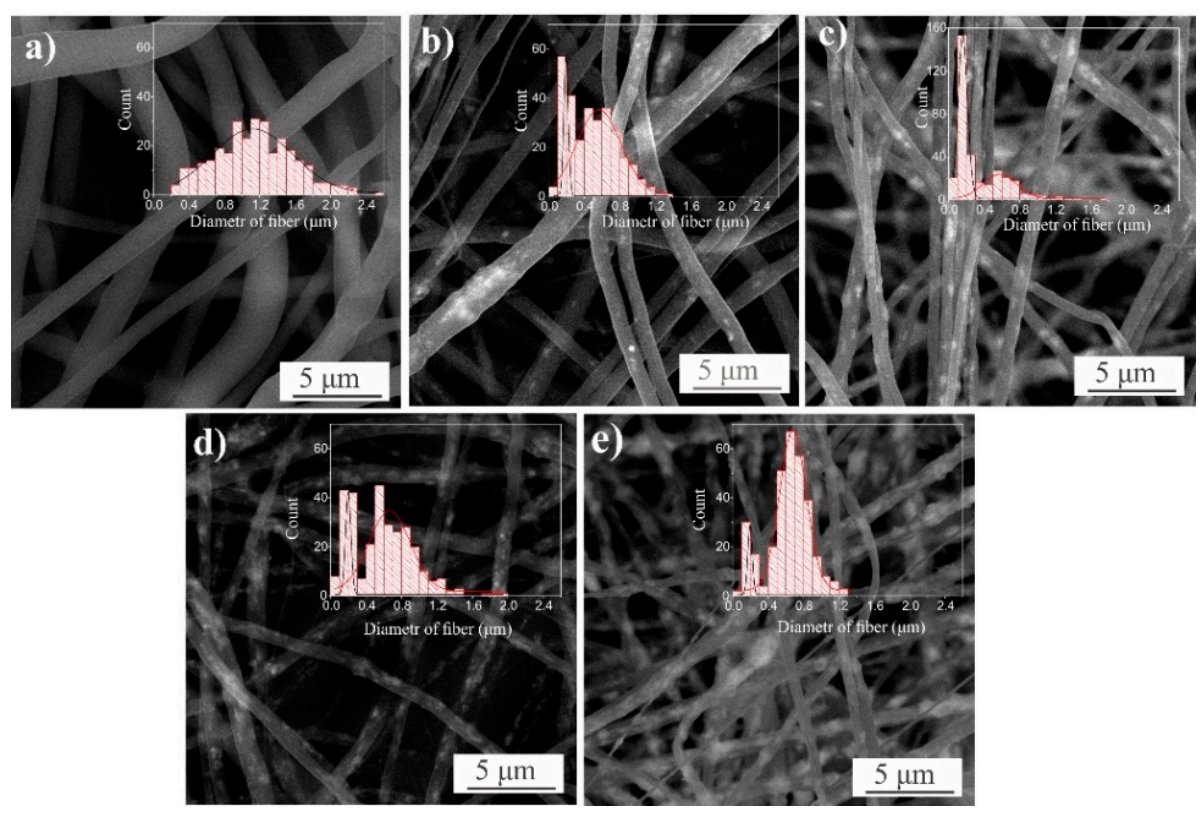

Figure 1. SEM images of PLLA (a) and PLLA/ZnO (b-e) membranes, with fiber diameters presented as histograms. ZnO NPs are loaded into the samples as: 0 (a), 5 (b), 10 (c), 20 (d), and 40 (e) wt.\%.

Table 1. Physical and mechanical characteristics of the as-prepared membranes (average \pm standard deviation).

\begin{tabular}{ccccccc}
\hline Sample & Density, $\mathbf{g} / \mathbf{c m}^{\mathbf{3}}$ & \multicolumn{2}{c}{$\begin{array}{c}\text { Average Fiber Diameter, } \boldsymbol{\mu m} \\
\text { (Peak Intensity) }\end{array}$} & $\begin{array}{c}\text { Water Contact } \\
\text { Angle } \mathbf{H}_{\mathbf{2}} \mathbf{O},{ }^{\circ}\end{array}$ & $\begin{array}{c}\text { Stretch, } \% \\
\text { Strength Limit, } \\
\mathbf{M P a}\end{array}$ \\
\hline PLLA & 0.15 & \multicolumn{2}{c}{$1.1(30)$} & $122 \pm 1$ & $62 \pm 5$ & $2.7 \pm 0.1$ \\
\hline PLLA/ZnO_5\% & 0.16 & $0.2(40)$ & $0.6(40)$ & $124 \pm 2$ & $35 \pm 1$ & $3.7 \pm 0.2$ \\
\hline PLLA/ZnO_10\% & 0.17 & $0.2(150)$ & $0.6(30)$ & $126 \pm 2$ & $30 \pm 4$ & $3.9 \pm 0.2$ \\
\hline PLLA/ZnO_20\% & 0.16 & $0.2(30)$ & $0.7(70)$ & $127 \pm 1$ & $44 \pm 2$ & $3.1 \pm 0.2$ \\
\hline PLLA/ZnO_40\% & 0.19 & $0.2(60)$ & $0.5(35)$ & $117 \pm 1$ & $48 \pm 7$ & $2.5 \pm 0.2$ \\
\hline
\end{tabular}

Figure 2 shows the SEM images and corresponding EDX maps of zinc $(\mathrm{ZnK} \alpha)$ and oxygen $(\mathrm{OK} \alpha)$ distribution obtained for samples PLLA/ZnO_5\% (a) and PLLA/ZnO_20\% (b). Note that the distribution of oxygen is somewhat more uniform in the fibers than that of $\mathrm{Zn}$, which is explained by $\mathrm{O}$ atoms present in both $\mathrm{ZnO}$ NPs and in the polymer. Fairly even distribution of $\mathrm{ZnO}$ NPs in PLLA fibers is observed, with $\mathrm{ZnO}$ agglomerates observed occasionally. Interestingly, increase in $\mathrm{ZnO}$ load from 5 to $20 \mathrm{wt}$ \% was found to result in the enrichment of the fiber surface with zinc oxide, which is seen in both SEM images (left-most images in Figure 2) and in those with Zn and O mapping. Distribution of carbon atoms is not shown in Figure 2 since the samples were analyzed on C-based substrates, making such results less informative. More detailed results obtained for all samples are presented in Supplementary Materials Figure S1. 

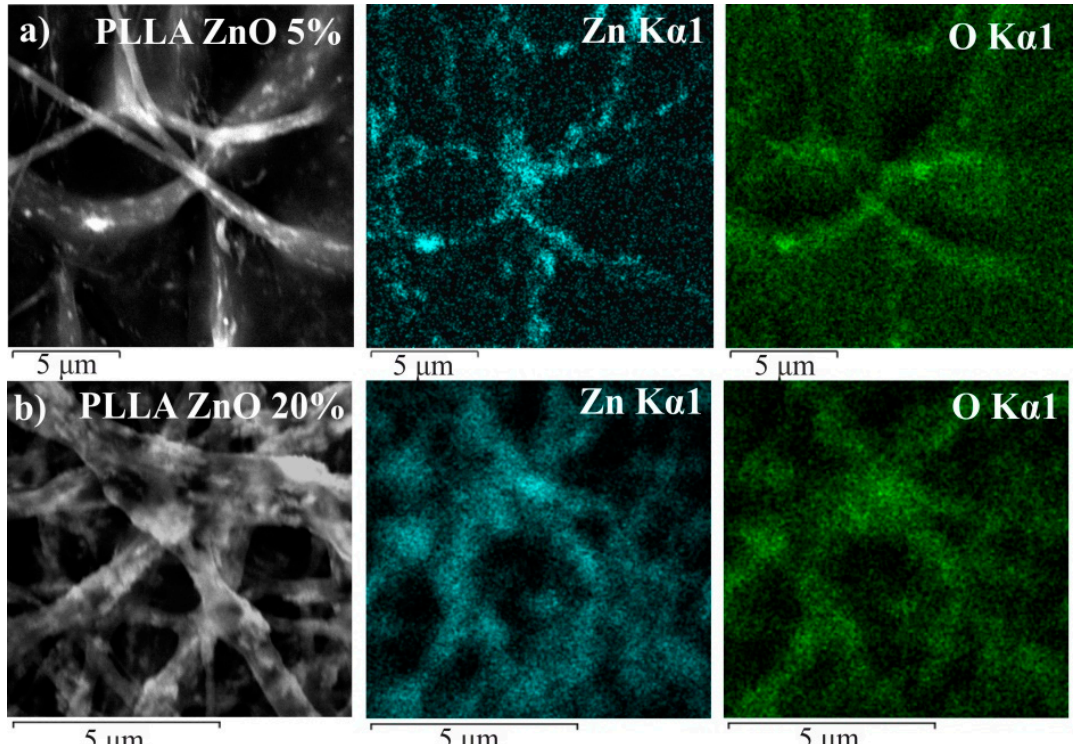

Figure 2. SEM images and corresponding EDX mapping for distribution of zinc ( $\mathrm{Zn} K \alpha 1)$ and oxygen (O K $\alpha 1)$. Data are presented for samples PLLA/ZnO_5\% (a) and PLLA/ZnO_20\% (b).

Influence of $\mathrm{ZnO} N P s$ on the crystalline state of the electrospun fibers of PLLA was studied by means of XRD, with XRD patterns of undoped and ZnO doped PLLA membranes shown in Figure 3. The pattern of pure PLLA membrane (black line) is seen to exhibit two distinct diffraction maxima and around $17.1^{\circ}$ and $19.3^{\circ}$, which correspond to the (200)/(110) and (203) planes of orthorhombic structure, respectively. Upon adding $5 \mathrm{wt} . \%$ of $\mathrm{ZnO}$ filler, the peaks of wurtzite $\mathrm{ZnO}$ are seen gradually to emerge in sample patterns, with their intensity increasing along the amount of incorporated ZnO NPs. At the same time, as well seen in the inset to Figure 3, the peaks of PLLA gradually decrease in intensity (see red, blue, pink, and green patterns that correspond to 5, 10, 20, and $40 \mathrm{wt} . \%$ of $\mathrm{ZnO}$ NPs). This observation clearly indicates that the increased content of incorporated $\mathrm{ZnO}$ NPs hinders crystallization of PLLA as NP aggregates limit the mobility of polymer chains [30].

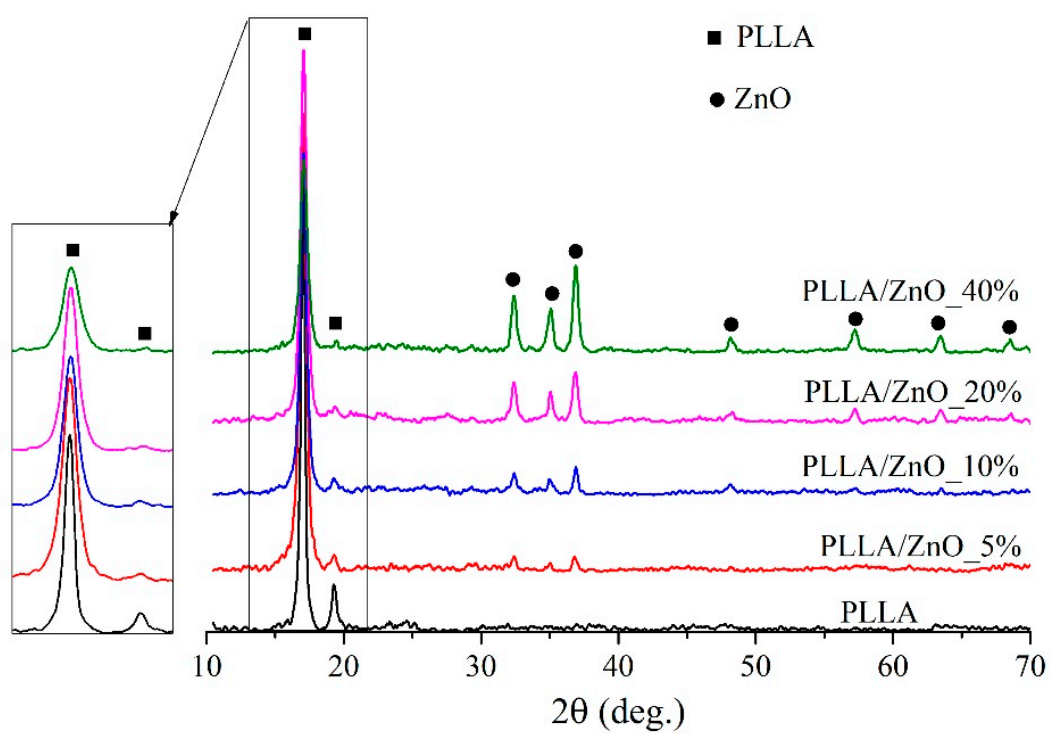

Figure 3. X-ray diffraction patterns of PLLA and PLLA/ZnO composite membranes.

Physical and mechanical properties of the prepared membranes are compared in Table 1. It is seen that the water contact angle of the pure PLLA membrane was $122^{\circ} \pm$ 
$1^{\circ}$, which is explained by the absence of any hydrophilic sites on its surface [31]. Increase in the amount of incorporated $\mathrm{ZnO}$ in the range of 5 to $20 \mathrm{wt} . \%$ is seen to not cause any considerable changes in the material's wettability, which is probably explained by the fact that ZnO NPs were embedded into the bulk of PLLA fibers (see Figure 1, panels (b)-(d)). However, further rise of the filler's load to $40 \mathrm{wt} . \%$ is seen in Table 1 to result in enhanced wetting properties (lower water contact angle) of sample PLLA/ZnO_40\%. This could be due to the presence of a larger number of ZnO NPs on the fiber surface, which agrees well with the above presented SEM and EDX results for another ZnO-rich sample, PLLA/ZnO_20\%. ZnO is well known as a hydrophilic material, and thus the appearance of patches with $\mathrm{ZnO}$ is expected to improve the polymer's hydrophilicity [19]. Previously, a similar decrease in water contact angle for polycaprolactone membranes filled with $\mathrm{ZnO}$ NPs was reported in [30].

Both strength limit and elongation at fracture were also determined for all prepared membrane samples. Addition of ZnO NPs in the amount of $10 \mathrm{wt} . \%$ is seen in Table 1 to lead to strength values up to 1.4 larger in comparison with that of the non-doped PLLA membrane (Table 1, column 7). There are three possible reasons for this finding. (1) The homogeneous dispersion formed at low $\mathrm{ZnO}$ concentrations in PLLA matrix leads to a uniform distribution of stresses in the fibers, as well as to minimal number of stress centers where stresses are transferred from the polymer to the filler [32]. (2) ZnO NPs are known to reinforce composites with polymer through formation of hydrogen bonds between the polymer (PLLA fibers in our case) and hydroxyl groups of ZnO NPs [20]. (3) Increase in the content of $\mathrm{ZnO}$ within the range of 5-10 wt.\% leads to an increase in density of the formed membranes, along with a decrease in the average fiber's diameter (Table 1). As a result, the volume of such $\mathrm{ZnO}$-doped membranes is formed by a larger number of fibers with a smaller diameter, which leads to reduced specific load on each fiber. In turn, this leads to a higher total strength of the membrane.

Incorporating more ZnO NPs into the PLLA matrix (in the range of 20-40 wt.\%) was found to result in $\mathrm{ZnO}$ agglomerates formed in the matrix (see Figure 1d,e). Consequently, along with a further decrease of fibers' diameter and PLLA crystallite sizes, this led to the formation of defects that acted as stress centers, which inhibit stress transfer between the polymer matrix and the filler (ZnO NPs). As seen in Table 1 (column 7), this resulted in a reduction of total membrane strength.

Figure 4 presents FTIR spectra of PLLA and PLLA/ZnO membranes, with the main bands belonging to polymer PLLA [33,34]. The strongest peak located at around $1754 \mathrm{~cm}^{-1}$ corresponds to the vibration of the $\mathrm{C}=\mathrm{O}$ bond, while symmetric and asymmetric bending vibration of $\mathrm{CH}_{3}$ groups were observed at 1454,1385, and $1362 \mathrm{~cm}^{-1}$. The bands seen at $1213-1132 \mathrm{~cm}^{-1}$ are assigned to valent and deformational asymmetric vibrations of bonds in the $\mathrm{COC}$ and $\mathrm{CH}_{3}$ groups. The peak with maximum at $1092 \mathrm{~cm}^{-1}$ is related to valent symmetric vibrations of the $\mathrm{COC}$ bonds, whereas valent vibrations of bonds $\mathrm{C}-\mathrm{CH}_{3}$ and C-COO manifest themselves at 1046 and $870 \mathrm{~cm}^{-1}$, respectively. Finally, the peak in the region from 550 to $430 \mathrm{~cm}^{-1}$ appears for samples incorporated with ZnO NPs and corresponds to the $\mathrm{Zn}-\mathrm{O}$ bending vibrations [35]. 


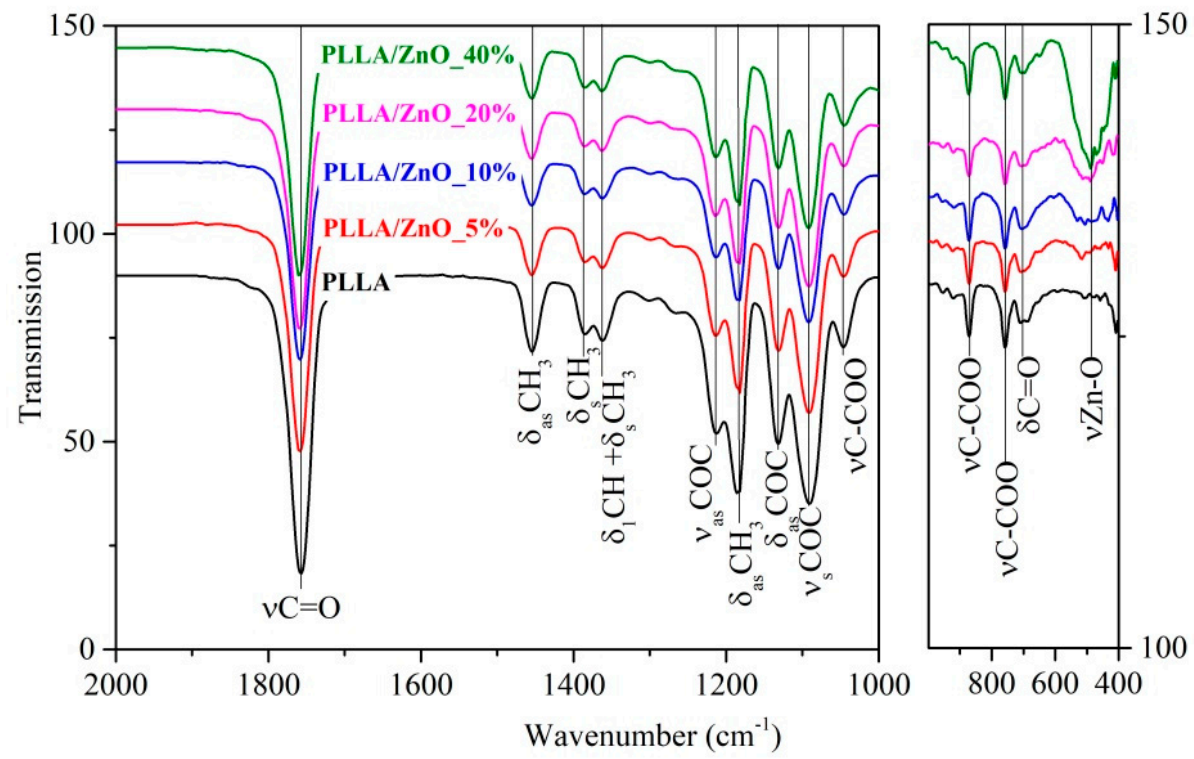

Figure 4. FTIR spectra of PLLA and ZnO-loaded PLLA membranes.

It is seen in Figure 4 that the increased amount of ZnO NPs doped into PLLA leads to higher intensity of the peak observed between 550 and $430 \mathrm{~cm}^{-1}$, which confirms that more nanomaterial was embedded as filler. Note that at elevated loads of ZnO NPs, the FTIR spectra of PLLA membranes do not exhibit any new lines or line shifts. This implies that the polymer-ZnO interaction is purely based on the Van der Waals forces with no covalent bonds forming. As the intensity of peak at around $1362 \mathrm{~cm}^{-1}$ decreases, this confirms that the incorporation of $\mathrm{ZnO}$ nanomaterial hinders crystallization in PLLA matrix [36].

Spectral and luminescent properties of all prepared samples are presented in Figure 5 (where similar spectra are also given for the laser-prepared ZnO NPs) and in Table 2. The absorption spectrum of ZnO NPs is seen in Figure 5a (green line) to have a strong maximum at $363 \mathrm{~nm}$, which is associated with the electron transition from the valence band to the conduction band. The bandgap of the used $\mathrm{ZnO}$ nanomaterial was thus evaluated to be $\mathrm{E}_{\mathrm{g}}=3.22 \mathrm{eV}$, being slightly lower than that of bulk $\mathrm{ZnO}(3.3 \mathrm{eV})$ [37]. The observed small difference can be explained by either the size effect or oxygen vacancies that introduce new states in the band gap of ZnO NPs laser-generated in air [38].

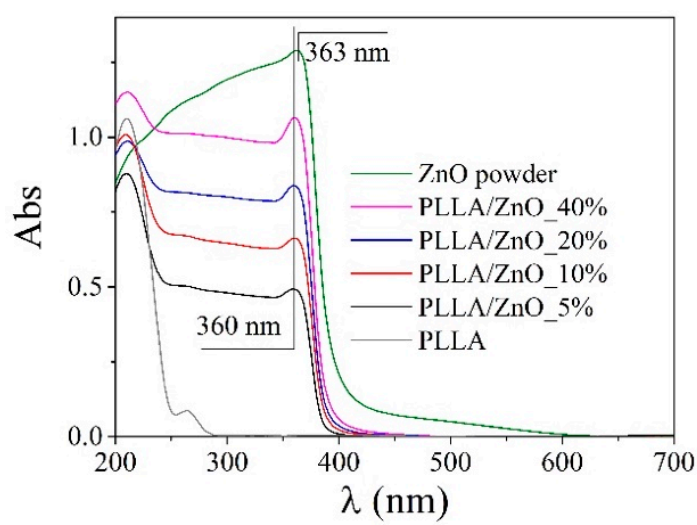

(a)

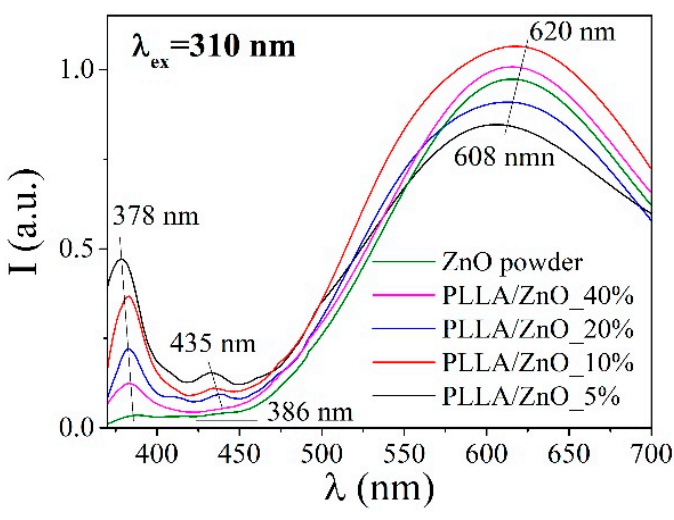

(b)

Figure 5. Absorption (a) and PL (b) spectra of prepared composite membranes. Spectra of laser-prepared ZnO NPs are given for comparison. 
Table 2. Spectral and luminescent properties of the obtained materials.

\begin{tabular}{cccc}
\hline \multirow{2}{*}{ Sample } & \multicolumn{2}{c}{ Luminescence } & \multirow{2}{*}{$\boldsymbol{\Delta E}, \mathbf{e V}$} \\
\cline { 2 - 3 } & $\boldsymbol{\lambda}_{\text {max }}, \mathbf{n m}$ & $\mathbf{I}_{\text {inter-band }} / \mathbf{I}_{\text {defect }} \mathbf{1}$ & \\
\hline PLLA & 431 & - & - \\
PLLA/ZnO_5\% & $379 / 435 / 612$ & 0.5 & 3.27 \\
PLLA/ZnO_10\% & $382 / 431 / 612$ & 0.3 & 3.27 \\
PLLA/ZnO_20\% & $382 / 439 / 608$ & 0.2 & 3.27 \\
PLLA/ZnO_40\% & $382 / 607$ & 0.08 & 3.27 \\
ZnO powder & $387 / 608$ & 0.04 & 3.22 \\
\hline
\end{tabular}

${ }^{1}$ The ratio of the intensity of interband and defect luminescence.

Upon incorporating ZnO NPs into PLLA polymer, the polymer samples are seen in Figure 5 a to demonstrate a small blueshift (by $3 \mathrm{~nm}$ ) of their absorption edge, which corresponds to larger values of their bandgap compared with the $\mathrm{ZnO}$ nanomaterial (Table 2). This finding is explained by coating of the semiconducting material with polymer [39].

The PL spectrum of the $\mathrm{ZnO}$ powder used as an antibacterial agent is seen in Figure $5 \mathrm{~b}$ to show a small exciton peak at $378 \mathrm{~nm}$ and a wide band at around $620 \mathrm{~nm}$, the latter band being related to various defects in crystal structure of $\mathrm{ZnO}[19,40,41]$. Meanwhile, in the ZnO-incorporated PLLA membranes, the peak at $380 \mathrm{~nm}$ was found to redshift, while the relative intensity of their defect-related emission decreased. This finding can be explained by surface passivation of $\mathrm{ZnO}$ nanomaterial embedded into the polymer. This effect is the most pronounced for sample PLLA/ZnO_5\% where the exciton-related peak at $378 \mathrm{~nm}$ is best seen in Figure $5 b$ (black line) [42].

\subsection{Antibacterial Properties of PLLA/ZnO Composite Membranes}

Figure 6 presents the results of antibacterial tests carried out with both non-doped PLLA and samples incorporated with ZnO NPs and with two bacterial strains: grampositive S. aureus (Figure 6a) and gram-negative E. coli (Figure 6b). The methodology used was based on the standard ISO 20743:2013, implying a direct contact of sample with a bacterial medium. Figure 6 compares the logarithmic values of the number of bacteria grown on the control sample (C, pure PLLA membrane in our case) and samples with antibacterial agent ( $T$, four PLLA/ZnO samples in our case) for the initial contact $\left(C_{0}\right.$ and $T_{0}$, contact time $0 \mathrm{~h}$ ) and after prolonged contact $\left(C_{\mathrm{t}}\right.$ and $T_{\mathrm{t}}$, contact time of $24 \mathrm{~h}$ ). According to the methodology [28], the antibacterial effect is observed when bacterial growth on a tested sample with antibacterial agent ( $G$, blue bars) is lower than that on the control sample ( $F$, blue bars with shading). Comparison of the green bars in Figure 6, corresponding to control sample $\left(C_{t}\right.$, green bars with shading) and those with ZnO NPs ( $T_{\mathrm{t}}$, green bars), clearly demonstrates that bacterial growth was suppressed on all $\mathrm{ZnO}$ incorporated membranes, which was observed for both the S. aureus and E. coli strains (Figure 6).

Hence, based on Figure 6 one can conclude that for all $\mathrm{ZnO}$-loaded membranes, antibacterial action was observed, which is manifested by inhibition of bacterial growth on such samples (for both tested bacteria strains). Note that an antibacterial agent is considered as bactericidal (when it kills bacteria), or as bacteriostatic (when it inhibits their growth). In the former case, the $G$ parameter in formula (1) must be $G<0$ (i.e., $T_{t}<T_{0}$ ), while in the latter case, it should be within the following range: $F>G \geq 0$. Obvious bactericidal behavior was only found for sample PLLA/ZnO_40\% towards S. aureus, i.e., the concentration of bacteria on its surface after incubation period was lower than that on the control sample, $\mathrm{ZnO}$-free PLLA $\left(T_{\mathrm{t}}<T_{0}\right)$. It is seen in Figure $6 \mathrm{a}, \mathrm{b}$ that the value of antibacterial activity $(A$, red bars in panels $(a, b))$ rises along with the amount of $\mathrm{ZnO}$ NPs loaded into PLLA fibers. It is noteworthy that antibacterial activity (seen as red bars in panels $(a, b))$ is considerably higher towards $S$. aureus when compared with the results observed for E. coli. This is believed to be related with the difference in the structure of membranes in these two bacteria $[19,43]$. The cell membrane of the E. coli is known to 
have a more complex structure, being thicker and chemically different from that of the S. aureus $[19,43]$.

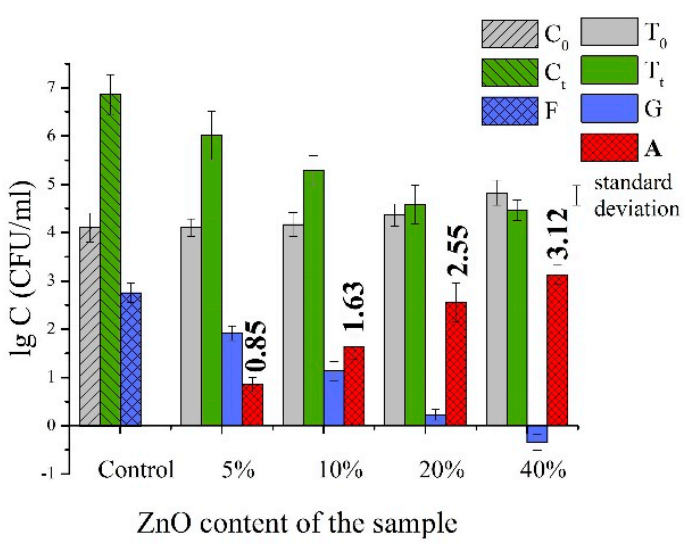

(a)

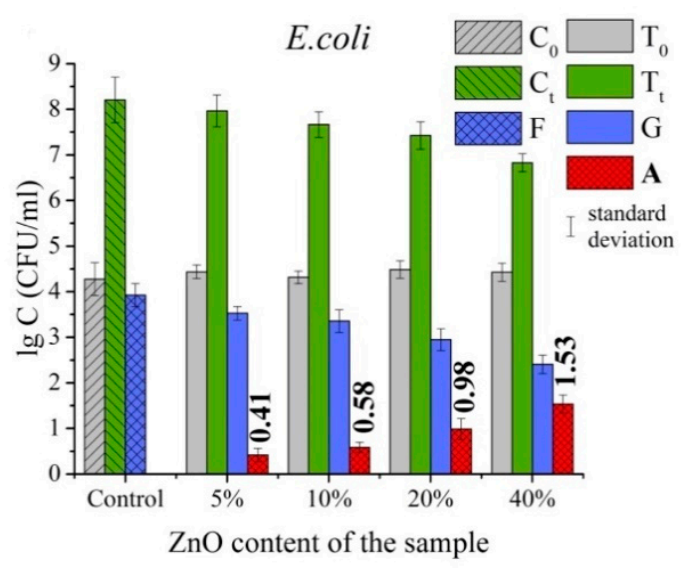

(b)

Figure 6. Results of antibacterial tests according to the ISO 20743:2013 standard obtained for S. aureus (a) and E. coli (b) bacteria.

There are several mechanisms explaining antibacterial action of ZnO NPs [44]: through the formation of reactive oxygen species (ROS), release of $\mathrm{Zn}^{2+}$ ions via partial $\mathrm{ZnO}$ dissolution, electrostatic sticking of $\mathrm{ZnO} N$ Ps to the bacterium membrane, and so on. All these mechanisms result in the decay of the bacterium cell membrane, thus causing its disfunction and penetration of destructive antibacterial species, such as ROS and $\mathrm{Zn}^{2+}$, inside the cell. Note that the process of internalization (i.e., absorption of the NP by the bacterium cell) is governed by the size, chemistry, morphology, defects, and even functionalization of the $\mathrm{ZnO}$ NP. For example, antibacterial activity of ZnO NPs was found to rise for smaller NPs since such particles have a larger surface area [45,46]. Besides, smaller ZnO NPs are known to have larger reactivities because of a greater number of forming ROS whose generation is also dependent on particle's surface area $[47,48]$.

Our previous studies showed that similar laser-generated ZnO NPs, when deposited on the surface of PLLA matrix, demonstrated high bactericidal action towards S. aureus and high bacteriostatic action towards E. coli bacteria [19]. In the present work, ZnO NPs were embedded into PLLA fibers, which limited access to the active surface of the NPs (Figure 7). This was expected to guarantee that such NPs would remain inside PLLA fibers without penetrating the treated tissue (e.g., inside the wound), providing a slower but longer release of $\mathrm{Zn}^{2+}$ ions and/or generation of ROS. At the same time, we also aimed at providing a biomedical material with primarily bacteriostatic effect (i.e., minimized bactericidal action), which inhibits bacterial growth and lets the host body act properly and kill bacteria through its own mechanisms.

Thus, the obtained results showed that the electrospun PLLA membranes with 5-10 wt.\% of ZnO NPs possessed better mechanical properties in comparison with their counterpart based on pure PLLA. This is believed to be due to uniform distribution of $\mathrm{ZnO}$ NPs and PLLA crystallites inside the composite fibers (Figure 7a). In this case, only small patches on fiber surface were found where $\mathrm{ZnO}$ material is exposed, which is why such samples demonstrated lower bacteriostatic behavior. In contrast, at higher loading amounts of ZnO NPs (20-40 wt.\%), the NPs tend to agglomerate, which prevents polymer's crystallization and leads to poorer mechanical properties of such membranes. At the same time, such ZnO-rich PLLA fibers have more $\mathrm{ZnO}$ NPs protruding from the fiber bulk (Figure $7 \mathrm{~b}$ ), which is why such membranes demonstrated a higher antibacterial effect. 


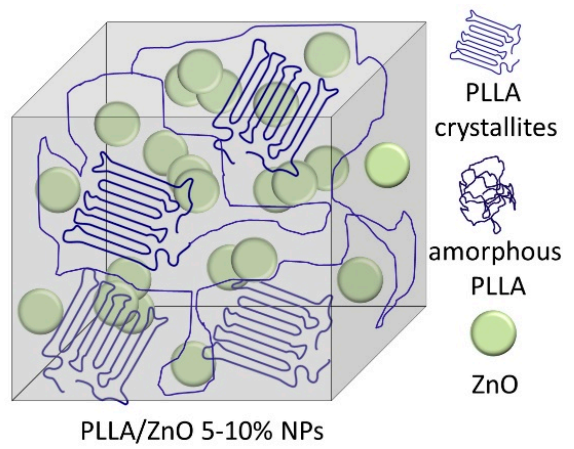

(a)

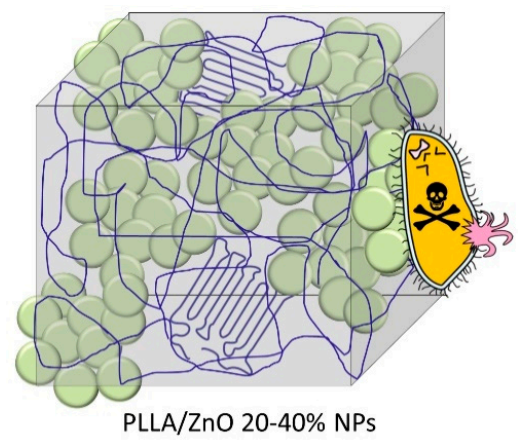

(b)

Figure 7. Schematic presentation of PLLA/ZnO membranes doped with smaller (a) and larger (b) amounts of ZnO NPs. ZnO NPs are distributed uniformly in the bulk of material presented in panel (a), while they were agglomerated and partially protrude on the surface of PLLA matrix in panel (b).

\section{Conclusions}

Polymer-based composites incorporated with inorganic nanoparticles produced via electrospinning are promising materials for nanomedicine. The present study used this inexpensive and efficient method to prepare composite membranes of poly-L-lactic acid (PLLA, or polylactide) incorporated with ZnO nanoparticles (NPs) generated via pulsed laser ablation of metallic $\mathrm{Zn}$ in air. Importantly, for the first time, this work prepared and tested PLLA membranes with as high content of incorporated ZnO NPs as 5-40 wt.\%. The following trends were observed when the amount of incorporated $\mathrm{ZnO}$ NPs was increased:

(i) Mechanical properties of the composite materials were enhanced for $\mathrm{ZnO}$ contents as high as $10 \mathrm{wt} . \%$, after which the material's strength was found to deteriorate. This is believed to be related to the NP-polymer interactions, as well as to particle distribution inside electrospun PLLA fibers. At high loads of $\mathrm{ZnO}$ (20-40 wt.\%), the incorporated NPs tended to agglomerate and crystallization of PLLA crystallites inside the fibers was hindered.

(ii) The antibacterial activity of the composite membranes increased monotonously. The as-prepared composites demonstrated bacteriostatic action towards the S. aureus, while this effect was somewhat lower towards the E. coli bacteria. At the maximum studied content of incorporated ZnO NPs (of $40 \mathrm{wt}$ \%), the PLLA/ZnO membrane exhibited a bactericidal effect towards the $S$. aureus bacteria.

The prepared composite membranes are believed to find applications as antibacterial dressings with prolonged action for treatment of purulent-inflammatory diseases of the skin and other soft tissues.

Supplementary Materials: The following are available online at https:/ / www.mdpi.com/1996-194 4/14/1/2/s1, Figure S1: SEM images and corresponding EDX maps of carbon (C K $\alpha 1)$, zinc (Zn $\mathrm{K} \alpha 1)$, and oxygen $(\mathrm{O} K \alpha 1)$ obtained for the samples.

Author Contributions: E.N.B. and V.A.S.: conceptualization; methodology. T.S.T. and D.A.G.: validation; formal analysis. A.A.A.: investigation; formal analysis. D.A.G. and A.L.N.: writingdraft. D.A.G., E.N.B. and S.A.K.: writing-review and editing; visualization. All authors have read and agreed to the published version of the manuscript.

Funding: This research was funded by the Tomsk State University Competitiveness Improvement Program. D.A.G was supported by a scholarship program of the President of the Russian Federation for young scientists and post-graduate students (SP-2018 Competition).

Acknowledgments: Characterization was carried out using equipment of the Tomsk Regional Common Use Centre, Tomsk State University.

Conflicts of Interest: The authors declare no conflict of interest. 


\section{References}

1. Armentano, I.; Bitinis, N.; Fortunati, E.; Mattioli, S.; Rescignano, N.; Verdejo, R.; Lopez-Manchado, M.A.; Kenny, J.M. Multifunctional nanostructured PLA materials for packaging and tissue engineering. Prog. Polym. Sci. 2013, 38, 1720-1747. [CrossRef]

2. Murariu, M.; Dubois, P. PLA composites: From production to properties. Adv. Drug Deliv. Rev. 2016, 107, 17-46. [CrossRef] [PubMed]

3. Raquez, J.-M.; Habibi, Y.; Murariu, M.; Dubois, P. Polylactide (PLA)-based nanocomposites. Prog. Polym. Sci. 2013, 38, 1504-1542. [CrossRef]

4. Jiang, J.; Pi, J.; Cai, J. The advancing of zinc oxide nanoparticles for biomedical applications. Bioinorg. Chem. Appl. 2018, 2018, 1-18. [CrossRef]

5. Abebe, B.; Zereffa, E.A.; Tadesse, A.; Murthy, H.C.A. A review on enhancing the antibacterial activity of ZnO: Mechanisms and microscopic investigation. Nanoscale Res. Lett. 2020, 15, 190. [CrossRef]

6. Fiedot-Tobola, M.; Ciesielska, M.; Maliszewska, I.; Rac-Rumijowska, O.; Suchorska-Wozniak, P.; Teterycz, H.; Bryjak, M. Deposition of zinc oxide on different polymer textiles and their antibacterial properties. Materials 2018, 11, 707. [CrossRef]

7. Svetlichnyi, V.; Shabalina, A.; Lapin, I.; Goncharova, D.; Nemoykina, A. ZnO nanoparticles obtained by pulsed laser ablation and their composite with cotton fabric: Preparation and study of antibacterial activity. Appl. Surf. Sci. 2016, 372, 20-29. [CrossRef]

8. Prasad, A.S.; Bao, B. Molecular mechanisms of zinc as a pro-antioxidant mediator: Clinical therapeutic implications. Antioxidants 2019, 8, 164. [CrossRef]

9. DiBaise, M.; Tarleton, S.M. Hair, nails, and skin: Differentiating cutaneous manifestations of micronutrient deficiency. Nutr. Clin. Pract. 2019, 34, 490-503. [CrossRef]

10. Alexander, J.; Tinkov, A.; Strand, T.A.; Alehagen, U.; Skalny, A.; Aaseth, J. Early nutritional interventions with zinc, selenium and vitamin D for raising anti-viral resistance against progressive COVID-19. Nutrients 2020, 12, 2358. [CrossRef]

11. Hackenberg, S.; Scherzed, A.; Kessler, M.; Froelich, K.; Ginzkey, C.; Koehler, C.; Burghartz, M.; Hagen, R.; Kleinsasser, N. Zinc oxide nanoparticles induce photocatalytic cell death in human head and neck squamous cell carcinoma cell lines in vitro. Int. J. Oncol. 2010, 37, 20-29. [CrossRef]

12. Cross, S.E.; Innes, B.; Roberts, M.S.; Tsuzuki, T.; Robertson, T.A.; McCormick, P. Human skin penetration of sunscreen nanoparticles: In-vitro assessment of a novel micronized zinc oxide formulation. Skin Pharmacol. Physiol. 2007, 20, 148-154. [CrossRef] [PubMed]

13. Osmond, M.J.; Mccall, M.J. Zinc oxide nanoparticles in modern sunscreens: An analysis of potential exposure and hazard. Nanotoxicology 2010, 4, 15-41. [CrossRef] [PubMed]

14. Valerini, D.; Tammaro, L.; Di Benedetto, F.; Vigliotta, G.; Capodieci, L.; Terzi, R.; Rizzo, A. Aluminum-doped zinc oxide coatings on polylactic acid films for antimicrobial food packaging. Thin Solid Films 2018, 645, 187-192. [CrossRef]

15. Bumbudsanpharoke, N.; Choi, J.; Park, H.J.; Ko, S. Zinc migration and its effect on the functionality of a low density polyethyleneZnO nanocomposite film. Food Packag. Shelf Life 2019, 20, 100301. [CrossRef]

16. Kumar, P.; Kumar, R. Investigations on rare earth activated $\mathrm{ZnO}$ nanoparticles reinforcement in polymer matrix for 3D printing application. In Reference Module in Materials Science and Materials Engineering; Elsevier: Hoboken, NJ, USA, 2020; pp. 51-61. [CrossRef]

17. Kamburova, K.; Boshkova, N.; Boshkov, N.; Radeva, T. Composite coatings with polymeric modified ZnO nanoparticles and nanocontainers with inhibitor for corrosion protection of low carbon steel. Colloids Surf. A 2021, 609, 125741. [CrossRef]

18. Fan, P.; Zhang, D.; Wu, Y.; Yu, J.; Russell, T.P. Polymer-modified ZnO nanoparticles as electron transport layer for polymer-based solar cells. Adv. Funct. Mater. 2020, 30, 2002932. [CrossRef]

19. Gavrilenko, E.A.; Goncharova, D.A.; Lapin, I.N.; Nemoykina, A.L.; Svetlichnyi, V.A.; Aljulaih, A.A.; Mintcheva, N.; Kulinich, S.A. Comparative study of physicochemical and antibacterial properties of $\mathrm{ZnO}$ nanoparticles prepared by laser ablation of $\mathrm{Zn}$ target in water and air. Materials 2019, 12, 186. [CrossRef]

20. Rodríguez-Tobías, H.; Morales, G.; Ledezma, A.; Romero, J.; Grande, D. Novel antibacterial electrospun mats based on poly(d,1lactide) nanofibers and zinc oxide nanoparticles. J. Mater. Sci. 2014, 49, 8373-8385. [CrossRef]

21. Lv, D.; Wang, R.; Tang, G.; Mou, Z.; Lei, J.; Han, J.; De Smedt, S.; Xiong, R.; Huang, C. Ecofriendly electrospun membranes loaded with visible-light-responding nanoparticles for multifunctional usages: Highly efficient air filtration, dye scavenging, and bactericidal activity. ACS Appl. Mater. Interfaces 2019, 11, 12880-12889. [CrossRef]

22. Liu, M.; Duan, X.-P.; Li, Y.-M.; Yang, D.-P.; Long, Y.-Z. Electrospun nanofibers for wound healing. Mater. Sci. Eng. C 2017, 76, 1413-1423. [CrossRef] [PubMed]

23. Dong, Y.; Thomas, N.L.; Lu, X. Electrospun dual-layer mats with covalently bonded ZnO nanoparticles for moisture wicking and antibacterial textiles. Mater. Des. 2017, 134, 54-63. [CrossRef]

24. Virovska, D.; Paneva, D.; Manolova, N.; Rashkov, I.; Karashanova, D. Electrospinning/electrospraying vs. electrospinning: A comparative study on the design of poly(l-lactide)/zinc oxide non-woven textile. Appl. Surf. Sci. 2014, 311, 842-850. [CrossRef]

25. Trujillo, S.; Lizundia, E.; Vilas, J.L.; Salmeron-Sanchez, M. PLLA/ZnO nanocomposites: Dynamic surfaces to harness cell differentiation. Colloids Surf. B 2016, 144, 152-160. [CrossRef]

26. GOST 3811-72. Textile materials. Textile fabrics, nonwonen fabrics and piece-articles. In Methods for Determination of Linear Dimensions, Linear and Surface Density, 4th ed.; GOST: Moscow, Russia, 1991. (In Russian) 
27. Tauc, J.; Grigorovici, R.; Vancu, A. Optical properties and electronic structure of amorphous germanium. Phys. Status Solidi 1966, 15, 627-637. [CrossRef]

28. ISO 20743:2013. Textiles—Determination of Antibacterial Activity of Textile Products, 2nd ed.; ISO: Geneva, Swizerland, 2013.

29. Huang, Z.-M.; Zhang, Y.-Z.; Kotaki, M.; Ramakrishna, S. A review on polymer nanofibers by electrospinning and their applications in nanocomposites. Compos. Sci. Technol. 2003, 63, 2223-2253. [CrossRef]

30. Augustine, R.; Kalarikkal, N.; Thomas, S. Effect of zinc oxide nanoparticles on the in vitro degradation of electrospun polycaprolactone membranes in simulated body fluid. Int. J. Polym. Mater. Polym. Biomater. 2016, 65, 28-37. [CrossRef]

31. Cassie, A.B.D.; Baxter, S. Wettability of porous surfaces. Trans. Faraday Soc. 1944, 40, 546. [CrossRef]

32. Tjong, S.C. Structural and mechanical properties of polymer nanocomposites. Mater. Sci. Eng. R 2006, 53, 73-197. [CrossRef]

33. Kister, G.; Cassanas, G.; Vert, M. Effects of morphology, conformation and configuration on the IR and Raman spectra of various poly(lactic acid)s. Polymer 1998, 39, 267-273. [CrossRef]

34. Srivastava, A.; Ahuja, R.; Bhati, P.; Singh, S.; Chauhan, P.; Vashisth, P.; Kumar, A.; Bhatnagar, N. Fabrication and characterization of PLLA/Mg composite tube as the potential bioresorbable/biodegradable stent (BRS). Materials 2020, 10, 100661. [CrossRef]

35. Gondal, M.A.; Drmosh, Q.A.; Yamani, Z.H.; Saleh, T.A. Synthesis of $\mathrm{ZnO}_{2}$ nanoparticles by laser ablation in liquid and their annealing transformation into ZnO nanoparticles. Appl. Surf. Sci. 2009, 25, 298-304. [CrossRef]

36. Zhang, J.; Duan, Y.; Sato, H.; Tsuji, H.; Noda, I.; Yan, S.; Ozaki, Y. Crystal modifications and thermal behavior of poly(-1-lactic acid) revealed by infrared spectroscopy. Macromolecules 2005, 38, 8012-8021. [CrossRef]

37. Srikant, V.; Clarke, D.R. Optical absorption edge of ZnO thin films: The effect of substrate. J. Appl. Phys. 1997, 81, 6357-6364. [CrossRef]

38. Liu, H.; Zeng, F.; Lin, Y.; Wang, G.; Pan, F. Correlation of oxygen vacancy variations to band gap changes in epitaxial ZnO thin films. Appl. Phys. Lett. 2013, 102, 181908. [CrossRef]

39. Tachikawa, S.; Noguchi, A.; Tsuge, T.; Hara, M.; Odawara, O.; Wada, H. Optical properties of ZnO nanoparticles capped with polymers. Materials 2011, 4, 1132-1143. [CrossRef]

40. Honda, M.; Goto, T.; Owashi, T.; Rozhin, A.G.; Yamaguchi, S.; Ito, T.; Kulinich, S.A. ZnO nanorods prepared via ablation of Zn with millisecond lase in liquid media. Phys. Chem. Chem. Phys. 2016, 18, 23628-23637. [CrossRef]

41. Goto, T.; Honda, M.; Kulinich, S.A.; Shimizu, Y.; Ito, T. Defects in ZnO nanoparticles laser-ablated in water-ethanol mixtures at different pressures. Jpn. J. Appl. Phys. 2015, 54, 070305. [CrossRef]

42. Sui, X.; Shao, C.; Liu, Y. Photoluminescence of polyethylene oxide-ZnO composite electrospun fibers. Polymer 2007, 48, 1459-1463. [CrossRef]

43. Sonohara, R.; Muramatsu, N.; Ohshima, H.; Kondo, T. Difference in surface properties between Escherichia coli and Staphylococcus aureus as revealed by electrophoretic mobility measurements. Biophys. Chem. 1995, 55, 273-277. [CrossRef]

44. Sirelkhatim, A.; Mahmud, S.; Seeni, A.; Kaus, N.H.M.; Ann, L.C.; Bakhori, S.K.M.; Hasan, H.; Mohamad, D. Review on zinc oxide nanoparticles: Antibacterial activity and toxicity mechanism. Nano Micro Lett. 2015, 7, 219-242. [CrossRef] [PubMed]

45. da Silva, B.L.; Caetano, B.L.; Chiari-Andreo, B.G.; Pietro, R.C.L.R.; Chiavacci, L.A. Increased antibacterial activity of ZnO nanoparticles: Influence of size and surface modification. Colloids Surf. B Biointerfaces 2019, 177, 440-447. [CrossRef] [PubMed]

46. Zarrindokht, E.-K. Antibacterial activity of $\mathrm{ZnO}$ nanoparticle on gram-positive and gram-negative bacteria. Afr. J. Microbiol. Res. 2012, 5, 440-447. [CrossRef]

47. Padmavathy, N.; Vijayaraghavan, R. Enhanced bioactivity of ZnO nanoparticles-An antimicrobial study. Sci. Technol. Adv. Mater. 2008, 9, 035004. [CrossRef]

48. Ohira, T.; Yamamoto, O.; Iida, Y.; Nakagawa, Z. Antibacterial activity of ZnO powder with crystallographic orientation. J. Mater. Sci. Mater. Med. 2008, 19, 1407-1412. [CrossRef] 